\title{
Genetic susceptibility to non-insulin dependent diabetes mellitus and glucose intolerance are located in HLA region
}

\author{
Eva Tuomilehto-Wolf, Jaakko Tuomilehto, Graham A Hitman, Aulikki Nissinen, Jari Stengård, \\ Juha Pekkanen, Paula Kivinen, Esko Kaarsalo, Martti J Karvonen
}

\begin{abstract}
Objectives-To test the hypothesis that the genetic susceptibility to non-insulin dependent diabetes mellitus is the same as that to insulin dependent disease and to see whether glucose intolerance is associated with specific HLA haplotypes.

Design-Population based study of men in 1989 first tested for glucose tolerance in 1984. HLA haplotypes, including HLA-A, C, B, DR, and DQ, were defined serologically. HLA haplotype data from a population based Finnish study of childhood diabetes were used for predicting non-insulin dependent diabetes and impaired glucose tolerance.

Setting-Two communities in Finland.

Subjects-Representative cohort of Finnish men aged $70-89$, comprising 98 men with non-insulin dependent diabetes mellitus and a randomly selected group of 74 men, who served as controls, who were tested for glucose tolerance twice within five years.

Main outcome measures-Non-insulin dependent diabetes, impaired glucose tolerance, blood glucose concentration.
\end{abstract}

Results-Diabetes associated HLA haplotypes were present in $94 \%(85 / 90)$ of diabetic subjects, $79 \%$ (27/34) of subjects with impaired glucose tolerance, and only $13 \%(3 / 23)$ of non-diabetic subjects. In this group of elderly men sensitivity of the diabetes associated HLA haplotypes for non-insulin dependent diabetes and impaired glucose tolerance was $90 \%$, specificity $87 \%$, and predictive power $97 \%$. Mean fasting blood glucose concentration was only just significantly higher in men with diabetes associated haplotypes than in men with no such haplotypes, but there was a substantial difference in blood glucose values two hours after glucose loading (10.4 and $6.4 \mathrm{mmol} / \mathrm{l}$ in men with diabetes associated HLA haplotypes and men with no such haplotypes, respectively $(\mathbf{p}<0 \cdot 0001))$.

Conclusions-These findings support the hypothesis that specific HLA haplotypes exhibit a common genetic determinant for insulin dependent and non-insulin dependent diabetes. Furthermore, HLA is a major genetic determinant of glucose intolerance in elderly Finnish men. The belief that the HLA predisposition to diabetes is specific for insulin dependent diabetes mellitus is largely incorrect.

Martti J Karvonen, professor emeritus

\section{Correspondence to:}

Eva Tuomilehto-Wolf,

National Public Health

Institute, Department of

Epidemiology and Health

Promotion, Elimäenkatu

25 A 6th Floor, FIN-00510

Helsinki, Finland.

$B M 7$ 1993;307:155-9

Both non-insulin dependent diabetes mellitus and insulin dependent diabetes are multifactorial diseases with a strong genetic basis. ${ }^{1-4}$ Progress in identifying genes involved in non-insulin dependent diabetes mellitus has been disappointingly slow. This is in contrast with the rapid advances in insulin dependent diabetes mellitus, in which the major genetic susceptibility can be explained by associations with HLA genes located on chromosome $6 .^{5-7}$ Phenotype studies of non-insulin dependent diabetes mellitus in white people have failed to find an association with HLA. This has been used as an argument that non-insulin dependent and insulin dependent forms of diabetes mellitus are genetically separate entities..$^{7-10}$ That there may be a common genetic basis between insulin dependent and non-insulin dependent diabetes mellitus has been suggested by several investigators. In 1950 Harris suggested that the difference between the two types of diabetes could be ascribed to a double dose of the gene in insulin dependent disease and a single dose of the gene in non-insulin dependent disease. ${ }^{11}$ Furthermore, familial clustering of the two types of diabetes has been observed..$^{12} 13$

Finland has the highest incidence of insulin dependent diabetes mellitus in the world. ${ }^{13-15}$ We have recently characterised the genetic susceptibility to insulin dependent diabetes mellitus in this ethnic group in a nationwide population based prospective family study-"childhood diabetes in Finland."1316 Non-insulin dependent diabetes mellitus in the adult population of Finland is also common, and a considerable proportion of elderly Finns have non-insulin dependent diabetes mellitus or impaired glucose tolerance. ${ }^{1718}$ Taken together with the fact that the population of Finland is genetically homogeneous, it is an ideal country in which to test the hypothesis that genetic factors responsible for insulin dependent and non-insulin dependent diabetes mellitus are the same.

The rationale that insulin dependent diabetes mellitus associated HLA haplotypes might also confer susceptibility to non-insulin dependent diabetes mellitus came from two observations. Firstly, seven of the 11 non-insulin dependent diabetes mellitus parents (nine fathers, two mothers) in the childhood diabetes in Finland study had transmitted insulin dependent diabetes mellitus associated high risk haplotypes to their insulin dependent diabetic offspring (table I). Secondly, $80 \%$ of non-diabetic family members who carried the insulin dependent diabetes mellitus associated high risk HLA-A2,Cw1,B56,DR4,DQw8 haplotype had a family history of non-insulin dependent diabetes mellitus. This haplotype has been found only in Finnish insulin dependent diabetes mellitus patients, in whom it confers the highest haplotype specific absolute risk of insulin dependent diabetes. ${ }^{16} 19$

Using HLA haplotype data from the childhood diabetes in Finland study, we tested the hypothesis that the genetic susceptibility to non-insulin dependent diabetes mellitus does not differ from that to insulin dependent diabetes mellitus.

\section{Subjects and methods}

Of a cohort of 1711 men born in two Finnish communities between 1900 and 1919 who were included in a multinational prospective cardiovascular 
disease study, 716 were tested for glucose intolerance..$^{17}$ In 1989, when the oral glucose tolerance test was repeated, the men were 70-89 years old-that is, old enough for most of the potentially diabetic subjects to have developed the disease. The participation rates in these surveys were over $90 \%$. The survey procedures have been described. ${ }^{17} 20-22$ In 1984 the blood glucose concentration was determined throughout the day for a capillary blood sample with a glucometer refractometer, and in 1989 it was determined in venous plasma with a Beckmann glucose analyser in the morning after an overnight fast.

METHODS OF HLA TYPING

Blood specimens were collected for HLA typing

TABLE I-Diabetes associated high risk HLA haplotypes in Finnish elderly men. Results expressed as numbers of subjects

\begin{tabular}{|c|c|c|c|c|c|c|c|c|c|}
\hline & & & & & & \multicolumn{4}{|c|}{ Diabetic status of elderly men } \\
\hline \multicolumn{6}{|c|}{ HLA haplotype } & \multirow{2}{*}{$\begin{array}{c}\text { Non-insulin } \\
\text { dependent } \\
\text { diabetes } \\
(\mathrm{n}=186)\end{array}$} & \multirow{2}{*}{$\begin{array}{c}\text { Impaired } \\
\text { glucose } \\
\text { tolerance } \\
(n=68)\end{array}$} & \multirow{2}{*}{$\begin{array}{l}\text { Unclear } \\
(n=44)\end{array}$} & \multirow{2}{*}{$\begin{array}{c}\text { Non- } \\
\text { diabetic } \\
(\mathrm{n}=46)\end{array}$} \\
\hline A & $\mathrm{C}$ & B & $\mathrm{Bw}$ & DR & DQ & & & & \\
\hline \multicolumn{10}{|c|}{37 Haplotypes transmitted from parents with insulin dependent diabetes or shared among haploidentical affected siblings } \\
\hline 2 & 1 & $\begin{array}{l}56 \\
56\end{array}$ & $\begin{array}{l}6 \\
6\end{array}$ & $\begin{array}{l}4 \\
4\end{array}$ & $\begin{array}{l}8 \\
8\end{array}$ & 3 & $\begin{array}{l}1 \\
0\end{array}$ & $\begin{array}{l}0 \\
0\end{array}$ & $\begin{array}{l}0 \\
0\end{array}$ \\
\hline 2 & 3 & 60 & 6 & 4 & 8 & 3 & 1 & 0 & 0 \\
\hline 24 & 3 & 60 & 6 & 4 & 8 & 2 & 0 & 0 & 0 \\
\hline 28 & 3 & 60 & 6 & 4 & 8 & 1 & 0 & 0 & 0 \\
\hline 2 & 3 & 62 & 6 & 4 & 8 & 7 & 1 & 1 & 1 \\
\hline 3 & 3 & 62 & 6 & 4 & 8 & 2 & 0 & 1 & 0 \\
\hline 24 & 3 & 62 & 6 & 4 & 8 & 0 & 0 & 0 & 0 \\
\hline 2 & 4 & 62 & 6 & 4 & 8 & 2 & 0 & 0 & 1 \\
\hline 2 & 7 & 18 & 6 & 4 & 8 & 1 & 1 & 0 & 0 \\
\hline 3 & 7 & 18 & 6 & 4 & 8 & 1 & 0 & 0 & 0 \\
\hline 30 & 5 & 18 & 6 & 4 & 8 & 1 & 0 & 0 & 0 \\
\hline 1 & 7 & 8 & 6 & 3 & 2 & 5 & 4 & 0 & 2 \\
\hline 2 & 7 & 8 & 6 & 3 & 2 & 1 & 3 & 1 & 0 \\
\hline 3 & 7 & 8 & 6 & 3 & 2 & 2 & 0 & 0 & 0 \\
\hline 28 & 7 & 8 & 6 & 3 & 2 & 4 & 2 & 2 & 0 \\
\hline 24 & 3 & 8 & 6 & 3 & 2 & 0 & 0 & 0 & 0 \\
\hline 33 & 8 & 14 & 6 & 3 & 2 & 1 & 0 & 0 & 0 \\
\hline 24 & 3 & 71 & 6 & 4 & 8 & 0 & 0 & 0 & 0 \\
\hline 24 & 7 & 39 & 6 & 4 & 8 & 0 & 0 & 0 & 0 \\
\hline 32 & 7 & 39 & 6 & 4 & 8 & 1 & 1 & 0 & 0 \\
\hline 2 & 4 & 35 & 6 & 4 & 8 & 1 & 0 & 0 & 0 \\
\hline 3 & 4 & 35 & 6 & 4 & 8 & 5 & 1 & 0 & 0 \\
\hline 24 & $\mathbf{x}$ & 51 & 4 & 4 & 8 & 0 & 1 & 0 & 0 \\
\hline 2 & 7 & 44 & 4 & 4 & 8 & 3 & 2 & 0 & 0 \\
\hline 3 & 7 & 44 & 4 & 4 & 8 & 0 & 0 & 0 & 0 \\
\hline 28 & 7 & 44 & 4 & 4 & 8 & 3 & 0 & 0 & 0 \\
\hline 32 & $\mathrm{x}$ & 44 & 4 & 4 & 8 & 1 & 0 & 0 & 0 \\
\hline 2 & 6 & 13 & 4 & 4 & 8 & 0 & 0 & 0 & 0 \\
\hline 3 & 6 & 13 & 4 & 4 & 8 & 0 & 0 & 0 & 0 \\
\hline 2 & 7 & 7 & 6 & 4 & 8 & 0 & 0 & 0 & 0 \\
\hline 3 & 3 & 7 & 6 & 1 & 5 & 0 & 0 & 0 & 0 \\
\hline 24 & 3 & 62 & 6 & 1 & 5 & 1 & 0 & 0 & 0 \\
\hline 2 & 3 & 60 & 6 & 2 & 6 & 2 & 0 & 0 & 0 \\
\hline 3 & 3 & 18 & 6 & 5 & 7 & 0 & 0 & 0 & 0 \\
\hline 2 & 6 & 13 & 4 & 7 & 2 & 1 & 2 & 0 & 0 \\
\hline 2 & 4 & 62 & 6 & 8 & 4 & 1 & 0 & 0 & 0 \\
\hline \multicolumn{10}{|c|}{2 Haplotypes transmitted from parents with non-insulin dependent diabetes } \\
\hline 3 & 7 & 7 & 6 & 6 & 6 & 4 & 3 & 1 & 0 \\
\hline 24 & 7 & 39 & 6 & 8 & 4 & 1 & 0 & 0 & 0 \\
\hline \multicolumn{10}{|c|}{18 Other diabetes associated haplotypes* } \\
\hline 2 & 1 & 56 & 6 & 6 & 6 & 1 & 0 & 0 & 0 \\
\hline 3 & 1 & 56 & 6 & 8 & 4 & 1 & 1 & 0 & 0 \\
\hline 2 & 3 & 60 & 6 & 1 & 5 & 2 & 0 & 0 & 0 \\
\hline 2 & 3 & 60 & 6 & 8 & 4 & 2 & 1 & 0 & 0 \\
\hline 3 & 3 & 60 & 6 & 4 & 8 & 2 & 0 & 0 & 0 \\
\hline 3 & 3 & 62 & 6 & 6 & 6 & 1 & 1 & 0 & 0 \\
\hline 24 & 3 & 62 & 6 & 1 & 5 & 1 & 0 & 0 & 0 \\
\hline 2 & 4 & 62 & 6 & 6 & 6 & 1 & 0 & 0 & 0 \\
\hline 28 & 3 & 62 & 6 & 1 & 5 & 2 & 0 & 0 & 0 \\
\hline 2 & 1 & 62 & 6 & 4 & 8 & 1 & 0 & 0 & 0 \\
\hline 2 & 3 & 62 & 6 & 8 & 4 & 4 & 1 & 1 & 0 \\
\hline 24 & 7 & 8 & 6 & 3 & 2 & 1 & 0 & 0 & 0 \\
\hline 24 & 1 & 39 & 6 & 4 & 8 & 1 & 0 & 0 & 0 \\
\hline 2 & $\mathbf{x}$ & 51 & 4 & 4 & 8 & 3 & 0 & 1 & 0 \\
\hline 2 & 1 & & 4 & 4 & 8 & 1 & 0 & 0 & 0 \\
\hline 24 & $\mathbf{x}$ & 44 & 4 & 4 & 8 & 2 & 0 & 0 & 0 \\
\hline 3 & 7 & 7 & 6 & 4 & 8 & 2 & 0 & 0 & 0 \\
\hline 2 & 7 & 7 & 6 & 6 & 6 & 2 & 1 & 0 & 0 \\
\hline
\end{tabular}

*Originated from insulin dependent diabetes mellitus associated haplotypes by substitution of one allele only. from the 98 living men who had been classified as diabetic in the 1984 survey and from 74 controls who had been classified as non-diabetic in 1984 (normal or impaired glucose tolerance). Controls were selected by using simple random sampling. In 1989 the mean body mass indices (weight $(\mathrm{kg}) / \mathrm{height}\left(\mathrm{m}^{2}\right)$ ) were $26 \cdot 4$ and 25.8 in diabetic men and controls, respectively, and the mean age was 77 years in both groups.

HLA-A,C,B,Bw,DR,DQ phenotypes were determined serologically in the 172 unrelated men by using 180 HLA antisera ( 120 class I, 60 class II) and the same test as in the childhood diabetes in Finland study. ${ }^{16}$ In three diabetic men DR and DQ results were not clear. DQ was defined either serologically or with sequence specific oligonucleotides or by nucleotide sequencing. ${ }^{193}$ All observed HLA phenotypes were transformed into the two most probable HLA haplotypes by two different algorithms - one taking known linkage disequilibrium into account and one assuming that all allelic combinations are equally possible. The assignments were based on 3528 Finnish haplotypes derived directly from 3314 HLA genotyped members of 882 different Finnish families ${ }^{16}$ - namely, 757 families with a newly diagnosed insulin dependent diabetic child from the childhood diabetes in Finland study and 125 non-diabetic control families. Four locus (A, C, B, and $\mathrm{DR}$ ) haplotype frequencies and three point delta values between the $\mathrm{A}, \mathrm{B}$, and $\mathrm{DR}$ loci were calculated. ${ }^{24}$

DEFINITION OF DIABETES ASSOCIATED HAPLOTYPES

In the childhood diabetes in Finland study HLA haplotypes were determined in 757 newly diagnosed children with insulin dependent diabetes aged 14 or under and their families nationwide. ${ }^{1316}$ Whole HLA haplotypes determined serologically by alleles of the class I loci A, C, and B and the class II loci DR and DQ were used as markers for susceptibility to insulin dependent diabetes mellitus. High risk insulin dependent diabetes associated HLA haplotypes were defined as those haplotypes which had been seen in families either as the haplotype transmitted from a parent with insulin dependent diabetes ( 66 families) to a child also with insulin dependent diabetes or as the haplotype shared among haploidentical siblings with insulin dependent diabetes (19 families) (table I). These high risk insulin dependent diabetes associated haplotypes carry the susceptibility gene (or genes) for insulin dependent diabetes except in the rare cases of recombination between the haplotype and the disease susceptibility locus (or loci). Thirty seven thus defined different high risk insulin dependent diabetes associated haplotypes were identified (table I). These 37 haplotypes explained the genetic susceptibility to insulin dependent diabetes in $83.8 \%(634 / 757)$ of the probands in the childhood diabetes in Finland study under the hypothesis that one high risk haplotype is sufficient to confer susceptibility to the disease.

Many of the haplotypes found in the 119 probands in the childhood diabetes in Finland study who did not carry the 37 high risk insulin dependent diabetes associated haplotypes differed from the high risk haplotypes by only one allele at either the A, C, or DR locus (table I). Eighteen of these haplotypes-all found to confer risk of insulin dependent diabetes in the childhood diabetes in Finland study or other studieswere also found in elderly Finnish men with noninsulin dependent diabetes and impaired glucose tolerance. As these 18 haplotypes undoubtedly originated from high risk insulin dependent diabetes associated haplotypes by substitution of one allele, they were also considered to be diabetes associated. Two additional haplotypes (HLA-A3,Cw7,B7,Bw6,DR6,DQ6 and A24,Cw7,B39,Bw6,DR8,DQ4) transmitted from a parent with non-insulin dependent diabetes to a child 
with insulin dependent diabetes (table I) were also considered to be diabetes associated. Thus there were 57 diabetes associated haplotypes defined by the above criteria.

Glucose tolerance status in men was defined according to World Health Organisation criteria ${ }^{10}$ as: (a) diabetes $(\mathrm{n}=90)$ when the criteria for diabetes were met either in 1984 or in 1989 (in 1984, 15 of the diabetic men were treated with oral agents and one with insulin; in 1989,19 were treated with oral agents, two with insulin, and two with both); (b) impaired glucose tolerance $(n=34)$ when the WHO criteria for impaired glucose tolerance (but not diabetes) were met either in 1984 or in 1989 and the patients had not been given hypoglycaemic drugs; and (c) normal glucose tolerance $(n=23)$ when both oral glucose tolerance tests (in 1984 and 1989) gave normal results. Men whose glucose tolerance status had not been determined either in 1984 or in $1989(n=22)$ and the three men whose DR and DQ typing results were inconclusive were excluded from some analyses. Thus 147 men were classified by glucose tolerance status according to WHO criteria.

We predicted glucose tolerance status by using HLA haplotype data in the 147 men, who were classified into two groups-(a) men with diabetes associated haplotypes as defined in tables I and II $(\mathrm{n}=114) ;(b)$ men without any diabetes associated haplotypes $(n=33)$.

\section{STATISTICAL ANALYSES}

HLA status (diabetes associated HLA haplotypes or no diabetes associated HLA haplotypes) in the 172 HLA phenotyped elderly men was assigned as diabetes associated when at least one of the 57 diabetes associated haplotypes was present, and as not diabetes associated when none of the diabetes associated haplotypes were present.

Differences in HLA antigen frequencies between diabetic men and men with normal glucose tolerance were tested by $\chi^{2}$ test with Yates's correction or Fisher's exact test and appropriate correction for the number of comparisons. We used analysis of variance to compare fasting and two hour post-challenge blood glucose values in men with diabetes associated HLA haplotypes with those in men who had no diabetes associated HLA haplotypes. Because the blood glucose distributions were skewed to the right logarithmic transformation of the data was used.

\section{Results}

In 131 of the 147 elderly men $(89 \%)$ for whom biochemical data were complete the diagnosis was correctly predicted by the HLA haplotype data (table II). Diabetes associated haplotypes were present in $94 \%(85 / 90)$ of diabetic men, $79 \%$ (27/34) of men with impaired glucose tolerance, and in only $13 \%(3 / 23)$ of non-diabetic men $\left(\chi^{2}=65.4 ; p<0.0001\right)$. Sensitivity (probability of correctly identifying men with diabetes or impaired glucose tolerance associated with HLA haplotypes) was high for diabetic men (90\%).

TABLE II-Prediction of abnormal glucose tolerance status by HLA. Results expressed as numbers of subjects

\begin{tabular}{|c|c|c|c|c|}
\hline \multirow[b]{2}{*}{ HLA haplotypes } & \multicolumn{3}{|c|}{ Glucose tolerance status } & \multirow[b]{2}{*}{ Tota } \\
\hline & Diabetes & $\begin{array}{l}\text { Impaired } \\
\text { glucose } \\
\text { tolerance }\end{array}$ & Normal & \\
\hline Diabetes associated & 85 & 27 & 3 & 115 \\
\hline No diabetes associated & 5 & 7 & 20 & 32 \\
\hline Total & 90 & 34 & 23 & 147 \\
\hline
\end{tabular}

Sensitivity was $90 \%$, specificity $87 \%$, and positive predictive power for diabetes associated HLA haplotypes $97 \%$. In two non-diabetic men two alternative haplotypes (one diabetes associated, one non-diabetes associated) were equally probable. They were therefore allocated one per each HLA haplotype status category.
TABLE III-Mean and standard deviations of blood glucose concentration (geometric values) by year and HLA haplotype status

\begin{tabular}{|c|c|c|c|c|c|c|}
\hline \multirow[b]{3}{*}{ Year } & \multicolumn{4}{|c|}{ HLA haplotypes } & \multirow[b]{3}{*}{$F$ value } & \multirow[b]{3}{*}{$\mathrm{p}$ Value } \\
\hline & \multicolumn{2}{|c|}{$\begin{array}{c}\text { Diabetes } \\
\text { associated }\end{array}$} & \multicolumn{2}{|c|}{$\begin{array}{l}\text { No diabetes } \\
\text { associated }\end{array}$} & & \\
\hline & No & $\begin{array}{l}\text { Mean } \\
\text { (SD) }\end{array}$ & No & $\begin{array}{l}\text { Mean } \\
(\mathrm{SD})\end{array}$ & & \\
\hline \multicolumn{7}{|c|}{ Fasting blood glucose (mmoln) } \\
\hline $\begin{array}{l}1984 \\
1989\end{array}$ & $\begin{array}{l}99 \\
95\end{array}$ & $\begin{array}{l}5.7(2.0) \\
6.4(2.5)\end{array}$ & $\begin{array}{l}33 \\
32\end{array}$ & $\begin{array}{l}5 \cdot 2(1 \cdot 1) \\
5 \cdot 8(2 \cdot 0)\end{array}$ & $\begin{array}{l}3 \cdot 01 \\
4 \cdot 17\end{array}$ & $\begin{array}{l}0.085 \\
0.043\end{array}$ \\
\hline Average & 95 & $6 \cdot 1(2 \cdot 0)$ & 32 & $5 \cdot 5(1 \cdot 4)$ & $4 \cdot 45$ & 0.037 \\
\hline \multicolumn{7}{|c|}{ Two hour post-challenge blood glucose (mmoll) } \\
\hline $\begin{array}{l}1984 \\
1989\end{array}$ & $\begin{array}{l}82 \\
79\end{array}$ & $\begin{array}{r}11 \cdot 7(2 \cdot 8) \\
9 \cdot 3(4 \cdot 1)\end{array}$ & $\begin{array}{l}31 \\
24\end{array}$ & $\begin{array}{l}7 \cdot 2(2 \cdot 8) \\
6 \cdot 1(3 \cdot 1)\end{array}$ & $\begin{array}{l}71 \cdot 68 \\
22 \cdot 31\end{array}$ & $\begin{array}{l}<0.0001 \\
<0.0001\end{array}$ \\
\hline Average & 74 & $10.4(2.7)$ & 23 & $6 \cdot 4(2 \cdot 0)$ & $64 \cdot 04$ & $<0.0001$ \\
\hline
\end{tabular}

Specificity (probability of correctly identifying nondiabetic men by absence of diabetes associated HLA haplotypes) was also high ( $87 \%)$. The predictive power for diabetes associated HLA haplotypes to detect abnormal glucose tolerance was $97 \%$.

Analysis of the elderly men restricted to the 37 different high risk insulin dependent diabetes associated haplotypes (rather than the full 57 diabetes associated haplotypes) still showed a highly significant difference among the three strata of men. Sixty three $(70 \%)$ men with non-insulin dependent diabetes, 11 $(32 \%)$ men with impaired glucose tolerance, and four (9\%) non-diabetic men had an insulin dependent diabetes associated haplotype $\left(\chi^{2}=34 \cdot 2 ; p<0 \cdot 00001\right)$.

\section{HLA ANTIGEN FREQUENCIES}

Neither HLA-A nor B antigen frequencies differed among the three strata of men (diabetic, impaired glucose tolerance, normal (data not shown)). The frequency of DR4 was significantly higher in diabetic men $(57 \%)$ than in non-diabetic men $(13 \%)(p=0.003$, corrected for the number of comparisons made).

BLOOD GLUCOSE CONCENTRATION AND HLA HAPLOTYPES

Mean fasting blood glucose concentration was significantly higher $(p=0.037)$ in men with diabetes associated HLA haplotypes than in men with no diabetes associated HLA haplotypes (table III). The two hour glucose challenge resulted in only a moderate rise in blood glucose concentration in men with no diabetes associated HLA haplotypes (mean value at two hours $6.4 \mathrm{mmol} / \mathrm{l}$ compared wth $5.5 \mathrm{mmol} / \mathrm{l}$ fasting). In men with diabetes associated HLA haplotypes the shift in blood glucose distribution was pronounced (mean value at two hours $10.4 \mathrm{mmol} / 1$ compared with $6 \cdot 1 \mathrm{mmol} / 1$ fasting). The difference in two hour post-challenge blood glucose concentration between the two strata according to HLA haplotype status was highly significant $(p<0.0001)$.

\section{Discussion}

Our study shows common HLA susceptibility genes for insulin dependent diabetes mellitus, non-insulin dependent diabetes mellitus, and impaired glucose tolerance in the Finnish population. Most of the HLA haplotypes which carried a high risk of insulin dependent diabetes also carried risk of non-insulin dependent diabetes in this group of elderly men. As most people with genetic susceptibility to insulin dependent diabetes never develop the disease, a proportion of the general population carry the susceptibility genes for insulin dependent diabetes. From the non-diabetic control families in the childhood diabetes in Finland study we estimate this proportion to be about $20-25 \%$ of the Finnish population. These people are likely to develop abnormal glucose tolerance in old age. 
We have also shown the value of defining haplotypes (by analysis of HLA-A, B, C, DR, and DQ as a whole) compared with the use of phenotypes (analysis of the same loci but each considered separately). Thus by using HLA diabetes associated haplotypes we identified almost all elderly men with diabetes (94\% compared with $13 \%$ of controls), whereas only half of the diabetic men were identified at the DR locus $(57 \%$ of diabetic men compared with $13 \%$ of controls possessed DR4) and no differences were found for HLA-A, B, C when considered separately. This may partly explain why in other studies which have been restricted to use of phenotypes only weak and inconsistent associations have been found between HLA phenotypes and noninsulin dependent diabetes.

Class I associations with non-insulin dependent diabetes have been reported in Xhosas (A2), ${ }^{25}$ Pima Indians (A2), ${ }^{26}$ Asian Indians (B61), ${ }^{27-29}$ West Indian blacks (B40), ${ }^{30}$ Finns (Cw4), ${ }^{31}$ Chinese (B45), ${ }^{32}$ Nauruans (early onset; B56), ${ }^{33}$ and Papuans (B62). ${ }^{34}$ In most of these studies those HLA antigens which are the most commonly seen in non-insulin dependent diabetic patients were also frequent in the background population. Furthermore, in certain isolated ethnic groups the background population shows a restricted HLA polymorphism and a high degree of homozygosity. For instance, in the Pima Indians only four HLA-A locus antigens are found, of which A2 and A24 are the most common, with frequencies of around $49 \% .{ }^{35}$ Actually, A2 and A24 antigens were found in several diabetes associated HLA haplotypes in the Finnish population.

Our cohort of elderly men in Finland is renowned for its high incidence of and mortality from cardiovascular disease. ${ }^{2022}$ Selection through cardiovascular disease mortality may indeed have removed some of the subjects with certain high risk insulin dependent diabetes associated HLA haplotypes. Four such haplotypes, all of which carried A24 and DR4,DQ8, were not seen in elderly men with non-insulin dependent diabetes. The importance of such selection is not known and warrants investigation.

A major problem in studies of genetics of noninsulin dependent diabetes has been that they have included people who may have been too young to develop diabetes. This weakens the probability of finding a true association. Secondly, many studies have used only known diabetic patients as index cases, leaving a considerable number of people with abnormal glucose tolerance among the "non-diabetic" groups. In our study the probability of such a misclassification was small. It is also unlikely that our patients had insulin dependent rather than non-insulin dependent diabetes, as most had been treated by diet alone over the five years. Furthermore, basal C peptide concentrations in those subjects tested were not compatible with the diagnosis of insulin dependent diabetes. Whether the factors determining glucose intolerance are the same in elderly men compared with middle aged men and women needs to be tested.

Our data suggest that the major histocompatibility complex contains a gene (or genes) which influences glucose homoeostasis. We suggest that susceptibility to $\beta$ cell damage is probably determined by several genes in the major histocompatibility complex and that genes in the HLA class I region modulate the risk determined by the HLA class II genes. With this hypothesis different polymorphic combinations of genes on the haplotype would determine the penetrance for diabetes. Thus the highest risk combinations would lead most frequently to insulin dependent diabetes mellitus, whereas lower risk combinations would lead to both non-insulin dependent and insulin dependent diabetes mellitus. The difference between the two types of diabetes is that in non-insulin dependent

\section{Clinical implications}

- More than one third of elderly people have either non-insulin dependent diabetes mellitus or glucose intolerance

- Non-insulin dependent diabetes mellitus has a strong genetic component, but identifying the relevant genes has been slow

- Almost all Finnish elderly men with noninsulin dependent diabetes mellitus $(94 \%$ in this study) carry HLA haplotypes known to confer susceptibility to insulin dependent diabetes mellitus in Finnish children

- Part of the genetic background of insulin dependent and non-insulin dependent diabetes mellitus is similar and coded by genes in the HLA region on chromosome 6

- The belief that the HLA predisposition to diabetes is specific for insulin dependent diabetes is largely incorrect

diabetes, owing to the lower penetrance of the HLA haplotypes the $\beta$ cell damage is not complete and is manifested only when associated with another cause of $\beta$ cell failure or insulin resistance. The cause of worsening glucose tolerance with age is poorly understood. However, it is clear from our study in elderly men that abnormal glucose tolerance is not an inevitable consequence of aging and that the main predisposition to abnormal glucose tolerance is determined by genes within the major histocompatibility complex.

In conclusion, HLA in the Finnish population is a common genetic determinant of both insulin dependent and non-insulin dependent diabetes mellitus and also of impaired glucose tolerance in men. The importance of our observation should be tested in a further study, including not only middle aged Finnish men with non-insulin dependent diabetes mellitus but also other ethnic groups with varying risk of diabetes.

Drs S Koskimies (Finnish Red Cross Blood Transfusion Service, Helsinki), E Du Toit (Provincial Laboratory for Tissue Immunology, Cape Town, South Africa), and J Vives (Hospital Clinic Servei D'Immunologia, Barcelona, Spain) kindly provided HLA antisera. Professors D Thomas (University of Southern California) and $M$ Boehnke (University of Michigan) advised in the development of a computer program for converting phenotypes to haplotypes. Comparative analyses were based on data obtained during the "childhood diabetes in Finland" study, which was partly supported by the National Institutes of Health (DK-37957), Sigrid Juselius Foundation, Nordisk Insulinfond, and the Association of the Finnish Life Insurance Companies. The Finnish seven countries study cohorts were studied with the support of the National Institutes of Health (AG087762), Academy of Finland, and the Sandoz Gerontological Foundation.

1 Neel JV. Diabetes mellitus: a geneticist's nightmare. In: Creutzfeldt W, Köbberling J, Neel JV, eds. The genetics of diabetes. Berling: Springer, 1976:1-11.

2 Pyke DA. Genetics of diabetes. In: Tattersall R, ed. Clinics in endocrinology and metabolism. Vol 6. London: W B Saunders, 1977:285-303.

3 Barnett AH, Eff C, Leslie RDG, Pyke DA. Diabetes in identical twins: a study of 200 pairs. Diabetologia 1981;20:87-93.

4 Bennett PH, Bogardus C, Tuomilehto J, Zimmet P. Epidemiology and natural history of non-insulin dependent diabetes mellitus: non-obese and obese. In: Albert KGMM, De Fronzo RA, Keen H, Zimmet P, eds. International textbook of diabetes mellitus. Chichester: John Wiley, 1992:147-76.

5 Singal DP, Blajchman MA. Histocompatibility (HL-A) antigens, lymphocytotoxic antibodies and tissue antibodies in patients with diabetes mellitus. Diabetes 1973;22:429-32.

6 Nerup J, Platz P, Andersson OO, Christy M, Lyngsoe J, Poulsen JE, et al. HLA antigens and diabetes mellitus. Lancet 1974; ;i:864-6.

7 Cudworth AG, Woodrow JC. Evidence for HL-A linked genes in juvenile diabetes mellitus. BMF 1975;iii: 133-5.

8 Arnaiz Vellena A, De Cordoba SR, Dujorne IL, Regueiro JR, Bootello A, Serrano-Rios M. HLA factors in non-insulin-dependent diabetes mellitus. Nengl F Med 1980;303:1065.

9 Tiwari JL, Terasaki PI. Endocrinology. In: $H L A$ disease associations. New York: Springer, 1985:210-2. 
10 World Health Organisation Study Group. Diabetes mellitus. WHO Tech Rep Ser 1985 ; No 727 .

11 Harris $\mathrm{H}$. The familial distribution of diabetes mellitus: a study of the relatives of 1241 diabetic propositi. Annals of Eugenics 1950;15:95-119.

12 Dahlqvist G, Blom L, Tuvemo T, Nyström L, Sandström A, Wall S. The Swedish childhood diabetes study. Results from a nine year case register and a one year case-referent study indicating that type 1 (insulin-dependent) a one year case-referent study indicating that type 1 (insulin-dependent)
diabetes mellitus is associated with both type 2 (non-insulin-dependent) diabetes mellitus is associated with both type 2 (non-insulin-depende
diabetes mellitus and autoimmune disorders. Diabetologia 1989;32:2-6.

13 Tuomilehto J, Lounamaa R, Tuomilehto-Wolf E, Reunanen A, Virtala E, Kaprio EA, et al. Epidemiology of childhood diabetes in Finland. Background of a nationwide study of type 1 (insulin-dependent) diabetes mellitus. Diabetologia 1992;35:70-6.

14 Diabetes Epidemiology Research International Group. Geographic patterns of childhood insulin-dependent diabetes mellitus. Diabetes 1988;37:1113-9.

15 Rewers M, LaPorte RE, King HOM, Tuomilehto J. Insulin-dependent diabetes mellitus in childhood: international patterns and trends. World Health Stat $Q 1988 ; 41: 179-89$

16 Tuomilehto-Wolf E, Tuomilehto J, Cepatis Z, Lounamaa R, DIME Study Group. New susceptibility haplotype for type 1 diabetes. Lancet 1989;ii:299302 .

17 Tuomilehto J, Nissinen A, Kivelä S-L, Pekkanen J, Kaarsalo E, Wolf E, et al. Prevalence of diabetes mellitus in elderly men aged 60 to 84 years in eastern and western Finland. Diabetologia 1986;29:611-5.

8 Tuomilehto J, Korhonen H, Kartovaara L, Salomaa V, Stengård JH, Pitkänen $\mathrm{M}$, et al. Prevalence of diabetes mellitus and impaired glucose tolerance in the middle-aged population of three areas in Finland. Int $\mathcal{f}$ Epidemiol 1991;20:1010-7.

19 Tienari PJ, Tuomilehto-Wolf E, Tuomilehto J, Peltonen L, Childhood Diabetes in Finland Study Group. HLA haplotypes in type 1 (insulindependent) diabetes mellitus: molecular analysis of the HLA-DQ locus. Diabetologia 1992;35:254-60.

20 Keys A, ed. Coronary heart disease in seven countries. Circulation 1970;41 (suppl 1):1-211.

21 Nissinen A, Kivelä S-L, Pekkanen J, Tuomilehto J, Kostiainen E, Piippo H, et al Levels of some biological risk indicators among elderly men in Finland. Age Ageing 1986;15:203-11.

22 Pekkanen J, Nissinen A, Puska P, Punsar S, Karvonen MJ. Risk factors and 25 year risk of coronary heart disease in a male population with a high incidence of the disease: the Finnish cohorts of the seven countries study. $B M \mathcal{F}$ 1989;299:81-5.
23 Tuomilehto-Wolf E, Tuomilehto J, Hitman G, Childhood Diabetes in Finland Study Group. DQA1 and DQB1 heterodimers in insulin-dependent diabetes mellitus: a genetic-epidemiological study in Finland. Ann Med 1992;24:533-8.

24 Baur MP, Neugebauer M, Albert ED. Reference tables of three-locus haplotype frequencies and delta values in Caucasians, orientals and
negroids. In: Albert ED, Baur MP, Mayr WR, eds. Histocompatibility negroids. In: Albert ED, Baur

25 Briggs BR, Botha MC, Jackson WPU, DuToit ED. The histocompatibility (HLA) antigen distribution in South African blacks (Xhosa). Diabetes 1980;29:68-70.

26 Williams C, Knowler WC, Butler WJ, Pettitt DJ, Lisse JR, Bennett PH, et al. HLA-A2 and type 2 (insulin-dependent) diabetes mellitus in Pima Indians: an association of allele frequency with age. Diabetologia 1981;21:460-3.

27 Serjeantson SW, Ryan DP, Ram P, Zimmet P. HLA and non-insulindependent diabetes mellitus in Fiji Indians. Med f Aust 1981;i:462-3.

28 Asmal AC, Dayal B, Jialal I, Leary WP, Omar MAK, Pillay NL, et al. Noninsulin-dependent diabetes mellitus with early onset in blacks and Indians. $S$ Afr Med f 1981;60:93-6.

29 Omar MAK, Hammond MG, Motala AA, Seedat MA. HLA class I and II antigens in South African Indians with non-insulin dependent diabetes mellitus. Diabetes 1988;37:796-9.

30 Wolf E, Drummond V, Savage M, Dean B, Bottazzo GF, Davidson JC, et al. HLA and islet cell antibodies in diabetics from the West Indies, Qatar and Brazil. Diabetologia 1981;21:A80.

31 Groop L, Koskimies S, Pelkonen R, Tolppanen E-M. Increased frequency of HLA-Cw4 in type 2 diabetes. Acta Endocrinol 1983;104:475-8.

32 Zhao $\mathrm{T}$, Chi $\mathrm{Z}$, Wang $\mathrm{H}$, Shen $\mathrm{M}$, Zhou $\mathrm{Z}$, Bu K, et al. HLA and diabetes mellitus in China. Chin Med f 1982;95:609-12.

33 Serjeantson SW, Owerbach D, Zimmet P, Nerup J, Thoma K. Genetics of diabetes in Nauru: effects of foreign admixture, HLA antigens and the insulin-gene-linked polymorphism. Diabetologia 1983;25:13-5.

34 Bhatia K, Patel M, Gorogo M. Type 2 (non-insulin dependent) diabetes mellitus and HLA antigens in Papua, New Guinea. Diabetologia 1984;27: 370-3.

35 Spees EK, Kostyu DD, Elston RC, Amos DB. HL-A profiles of the Pima Indians of Arizona. In: Dausset J. Colombani J, eds. Histocompatibility testing. Copenhagen: Munksgaard, 1973:345-9.

(Accepted 11 May 1993)

\title{
Routine ultrasonography in utero and subsequent handedness and neurological development
}

\author{
Kjell Å Salvesen, Lars J Vatten, Sturla H Eik-Nes, Kenneth Hugdahl, Leiv S Bakketeig
}

\section{Abstract}

Objective-To examine any associations between routine ultrasonography in utero and subsequent brain development as indicated by non-right handedness at primary school age and neurological development during childhood.

Design-Follow up of 8 and 9 year old children of women who took part in two randomised, controlled trials of routine ultrasonography during pregnancy.

Setting-Clinics of 60 general practitioners in Norway during 1979-81. Maternal and child health centres.

Subjects-2161 (89\%) of 2428 eligible singletons were followed up, partly through a questionnaire to their parents and partly through information from health centres.

Main outcome measures-The dominant hand of the child was assessed by 10 questions. Deficits in attention, motor control, and perception were evaluated by five questions. Impaired neurological development during the first year of life was assessed by an abbreviated version of the Denver developmental screening test.

Results-The odds of non-right handedness were higher among children who had been screened in utero than among control children (odds ratio 1.32; $95 \%$ confidence interval 1.02 to $1 \cdot 71)$. No clear differences were found between the groups with regard to deficits in attention, motor control, and perception or neurological development during the first year of life.

Conclusion-Our data suggest a possible association between routine ultrasonography in utero and subsequent non-right handedness, whereas no association with impaired neurological development was found. As the question on non-right handedness was one of six initial hypotheses, the observed results may be due to chance. None the less, the results suggest that the hypothesis may have some merit and should be tested in future studies.

\section{Introduction}

The common indications for diagnostic ultrasound scanning in pregnancy and the routine screening offered in some countries result in most pregnant women in developed countries being exposed to the procedure. No adverse effects of diagnostic ultrasound screening in pregnancy have been reported. Possible long term effects among children exposed to ultrasound in utero, however, have been examined in only a few studies. The general consensus is that further research on this topic is warranted.'

Abnormal development is typically related to disturbances during critical stages of gestation. Routine ultrasonography is usually done between the 16th and the 22nd week of pregnancy, which is an important phase of brain development. ${ }^{2}$ At this point neurones migrate towards their destination in the fetal brain. Experimental studies in vitro have shown changes in the cell membrane ${ }^{3}$ and cell surface motility and architecture ${ }^{4}$ after exposure to ultrasound. Ultrasound might influence neuronal migration, and it has been suggested that altered cerebral dominance, dyslexia, or impaired neurological development may be the result of a disturbed migration of neurones. ${ }^{5}$ The dominant hand may serve as an indicator of cerebral dominance. The normal high prevalence of right handedness means that random damage to the hemispheres will increase left handedness. ${ }^{6}$ 